\title{
Expert Retrieval Structures and Prospective Memory in the Cognition of Acheulian Hominins
}

\author{
Nira Alperson-Afil1', Naama Goren-Inbar², Gadi Herzlinger ${ }^{2,3}$, Thomas Wynn ${ }^{4}$ \\ ${ }^{1}$ Institute of Archaeology, Department of Land of Israel Studies and Archeology, Bar-Ilan University, Ramat-Gan, Israel \\ ${ }^{2}$ Institute of Archaeology, The Hebrew University of Jerusalem, Jerusalem, Israel \\ ${ }^{3}$ The Jack, Joseph and Morton Mandel School for Advanced Studies in the Humanities, The Hebrew University of Jerusalem, \\ Jerusalem, Israel \\ ${ }^{4}$ Department of Anthropology, University of Colorado, Boulder, USA \\ Email: nira.alperson-afil@biu.ac.il
}

How to cite this paper: Alperson-Afil, N., Goren-Inbar, N., Herzlinger, G., \& Wynn, T. (2020). Expert Retrieval Structures and Prospective Memory in the Cognition of Acheulian Hominins. Psychology, 11, 173189.

https://doi.org/10.4236/psych.2020.111012

Received: December 15, 2019

Accepted: January 14, 2020

Published: January 17, 2020

Copyright $\odot 2020$ by author(s) and Scientific Research Publishing Inc. This work is licensed under the Creative Commons Attribution International License (CC BY 4.0).

http://creativecommons.org/licenses/by/4.0/

cC (i) Open Access

\begin{abstract}
The range of evidence at the archaeological site of Gesher Benot Ya'aqov (GBY) provides a window into the minds of 800,000-year-old Acheulian hominins. Detailed action sequences used in stone tool manufacture, and in the exploitation of animals (over 70 taxa) and plants (over 130 taxa) are reconstructed, suggesting hierarchically organized decision chains with multiple alternative pathways to completion. In terms of complexity and organization, these action sequences rival those of modern hunters and gatherers and are typical of a cognitive strategy known in psychology as expert cognition, or expertise. In the modern world expert cognition drives many of our most esteemed activities, including chess, sport, musical performance, and medical diagnosis. Cognitive models of expertise emphasize the role of retrieval structures, which are chunks of information activated in working memory and linked by association to much larger chunks of information held in long-term memory. The evidence from GBY documents the importance of long-term memory, prospective memory, and cognitive control, and suggests that expert cognition has been an important strategy in hominin cognition for at least 800,000 years.
\end{abstract}

\section{Keywords}

Expert Cognition, Retrieval Structure, Prospective Memory, Acheulian, Hunting and Gathering

\section{Introduction}

The uniqueness of human cognition is expressed in social interaction, thoughts, 
and beliefs, which go beyond material culture remains. The latter is the common substance of archaeological research, and it is only at about 45,000 years ago that fully fledged modern cognition, associated with ornaments, mobile and cave art, have been recognized and attributed to modern humans. The material culture of earlier hominins mostly lacks artistic expressions and is dominated by stone artifacts whose makers are thereby considered by default less evolved (e.g., Herrmann et al., 2007). Stone artifacts are used by archaeologists to study the cognition of ancient hominins, applying a variety of approaches, including comparison to other tool-using primates (Schick et al., 1999), monitoring modern brain activity during knapping (Stout et al., 2000; Hecht et al., 2014) and evaluating the skill, dexterity, and cognitive abilities using psychological models (Herzlinger et al., 2017; Feizi et al., 2018).

\section{Literature Review}

Evolutionary cognitive archaeologists have made several proposals concerning the cognitive abilities of Acheulean hominins. Some consider the entire 1.5-millionyear Acheulean tradition as a whole, but most interpretations are valid only for the better-known later phases, after 800,000 years ago. Some of these have focused on fairly narrowly circumscribed abilities drawn from the cognitive science literature, including aesthetic cognition (Martin-Loeches, 2017; Berland \& Wynn, 2018), cognitive control and working memory (WM) (Twomey, 2013; Stout et al., 2015; Coolidge \& Wynn, 2018), spatial cognition (Wynn, 2002), levels of intentionality (Cole, 2017), and Theory of Mind (ToM) (Dunbar et al., 2014). Others have taken a broader approach, addressing such general domains as fluid intelligence (Mithen, 1996), social cognition (Goren-Inbar, 2011), information processing (Gowlett, 1979; Bernard, 2010), social learning, skill, semiotics (Gärdenfors \& Högberg, 2017; Stout \& Hecht, 2017), and art (Goren-Inbar, 2011; Bednarik, 2003). A few have eschewed the mind/body dualism of the Cartesian stance altogether and explored the Acheulean record from the vantage of Gibsonian psychology (Bril et al., 2012) and extended/embodied cognition (Malafouris, 2013), and in doing so drawn attention to the ways the tool-toolmaker interaction could produce a very different kind of mindedness.

From these studies, it is possible to hazard several generalizations about the later phases of Acheulean cognition. Many of the identified cognitive abilities appear to have been quite modern. For example, late Acheulean spatial cognition included the allocentric visualization abilities required for the mental rotation tasks so popular in IQ tests (Wynn, 2002); indeed it appears likely that the entire suite of human spatial cognitive abilities was in place by this time. However, some important modern cognitive abilities are nowhere evident in the Acheulean record. Most salient are abstract reasoning (e.g., relying on classes of phenomena that shared only intangible features) and true symbolic thought (with arbitrary reference). Recognizing these is undoubtedly difficult, but it is not impossible. Both abstract and symbolic thinking are clearly evident in archaeological 
remains of modern humans as early as 100,000 years ago. For earlier hominins there are only enigmatic hints, such as the Berekhat Ram figurine (Goren-Inbar \& Peltz, 1995). The assumption that late Acheulean hominins $(<800,000)$ were cognitively modern in many respects, but not in all, is supported by fossil evidence demonstrating brain sizes in the low end of the modern range (Rightmire, 2004).

In this paper, we use the psychological model of expert cognition (Ericsson \& Kintsch, 1995; Gobet, 2016) to examine the cognitive abilities of early Acheulian hominins who lived at Gesher Benot Ya'aqov (GBY) 800,000 years ago and engaged in the procurement and processing of faunal, floral, and lithic resources. Here we present a novel cognitive interpretation of this evidence, and suggest that in most respects the technically mediated cognition of these hominins was very similar to that of modern hunters and gatherers, the only obvious difference being an apparent dearth of innovation and an absence of material symbols.

\section{Gesher Benot Ya'aqov}

Excavations at GBY revealed over 20 superimposed archaeological horizons (sites), located on the shores of the paleo-Lake Hula in the Dead Sea Rift, on the route from Africa to Eurasia. Its waterlogged sediments document a fresh water lake margin environment encompassing some 100,000 years of hominin occupation (Marine Isotope Stages 18 - 20) dating to 800,000 years ago (Goren-Inbar et al., 2000). Rapid sealing preserved a sedimentary archive rich in lithic, paleontological, and paleobotanical remains, minimally disturbed taphonomically (Feibel, 2004; Alperson-Afil \& Goren-Inbar, 2010; Ashkenazi et al., 2010; Rabinovich et al., 2012; Goren-Inbar et al., 2018). The lake margin provided the hominins with optimal conditions within a small geographical zone, bounded by elevated terrains on the east and west. Wet and terrestrial habitats furnished a year-round availability of fresh water and diverse ecological niches rich in floral, faunal, and lithic resources. This biomass attracted Acheulian hominin groups who camped there repeatedly, producing lithic artifacts, systematically exploiting and processing terrestrial and aquatic animals, gathering plant food, and using fire (GorenInbar et al., 2002b; Alperson-Afil \& Goren-Inbar, 2010; Rabinovich et al., 2012; Goren-Inbar et al., 2018).

Analyses of the lithic assemblages (Goren-Inbar et al., 2018) demonstrated that the different raw materials were selected for particular tasks and predetermined target artifacts. The long lithic cultural sequence exhibits both variability, expressed in the composition and frequencies of tool types, and conservatism, expressed in the technological and typological traditions (Goren-Inbar et al., 2018; Sharon et al., 2011).

The hominins of GBY adopted different reduction sequences for each of the raw materials, differing in length and in the number of target artifacts. Moreover, in order to achieve their objectives, the knappers adjusted the knapping processes to handle unpredictable circumstances (e.g. modifying a broken li- 
mestone percussive tool into a core to produce flakes (Alperson-Afil \& Goren-Inbar, 2015). Analyses of the reduction processes illustrate that the knappers used diverse core sizes (e.g. giant basalt cores vs. small flint cores) and core methods. Furthermore, during a single reduction sequence they were able to alternate between different reduction strategies while using percussors of different materials, sizes, and hardness. Like other aspects of subsistence, the realm of knapping required mobility, expressed in the introduction of not only raw materials but of semi-finished and finished tools, into and from the site (Sharon \& Goren-Inbar, 1999; Madsen \& Goren-Inbar, 2004; Goren-Inbar \& Sharon, 2006).

The hominins of GBY had detailed knowledge of their environment, the multiple resources it provided, and their seasonal availability (Goren-Inbar et al., 2002a, 2002b; Rabinovich \& Biton, 2011; Rabinovich et al., 2012; Melamed et al., 2016; Goren-Inbar et al., 2018). In addition, evidence in both faunal and botanical assemblages indicates that the hominins exploited preferred species, a pattern documented throughout the depositional sequence.

Analyses of the rich paleobotanical assemblages of GBY resulted in the identification of over 130 taxa, 76 of which were identified to the species level (Melamed et al., 2016). Of these 55 taxa are edible plants that include nuts, fruits, seeds, vegetables, and plants producing underground storage organs (Melamed et al., 2016).

Animal exploitation included over 70 taxa and 34 identified species. These include fish (13 species, with marked abundance of large carps (Alperson-Afil et al., 2009; Zohar \& Biton, 2011)), amphibians (5 taxa, (Biton et al., 2018)), reptiles (4 species, (Biton et al., 2018)), birds (19 taxa, (Simmons, 2004)), and micro mammals (12 mammals, (Goren-Inbar et al., 2000; Rabinovich \& Biton, 2011)). There was a clear preference for medium and large mammals (19 species, (GorenInbar et al., 1994; Rabinovich \& Biton, 2011; Rabinovich et al., 2012)), particularly cervids, elephants, and hippos. Carcasses of large mammals were processed at the site (elephants, rhinos, large bovids, and hippos) and were likely driven to the lake edge, as their weight would have prohibited transportation. Small and mediumsized carcasses, predominated by fallow deer (Dama sp.), were transported to the site where they were systematically exploited and processed.

The variety of resources were transported to the lake margin and processed there. Analyses of the spatial distributions of the various occupational levels suggest that activities were spatially organized. The controlled use of fire is documented throughout the occupational sequence and is spatially associated with percussive activities and the exploitation of terrestrial and marine fauna (GorenInbar et al., 1994; Goren-Inbar et al., 2002a; Alperson-Afil et al., 2009; Alperson-Afil \& Goren-Inbar, 2010; Zohar \& Biton, 2011; Rabinovich et al., 2012; Melamed et al. 2016; Goren-Inbar et al., 2018).

\section{GBY Technical Sequences of Activities}

GBY provides a wealth of direct and indirect evidence of technically mediated 
activities. Here we focus on four of the most informative examples, including processing of fallow deer carcasses, exploitation of prickly water lily nuts, production of cleavers, and proximal modification of flint flake tools. In our chains of inference we begin with patterns of archaeological data, identify the activities that produced it, and then derive cognitive implications using a formal model of cognition (following (Coolidge \& Wynn, 2001; Wynn, 2002; Wynn \& Coolidge, 2011; Coolidge et al., 2015)). The length of these technically mediated sequential activities varies but they all exemplify the nature of hominin planning, knowhow, and decision making (Figure 1).

\subsection{Processing of Fallow Deer Technical Sequence}

Taphonomic analyses of fallow deer remains (Zohar \& Biton, 2011; Rabinovich et al., 2012) show that hominin expertise in handling this species was manifested in a technical sequence that started with the procurement of complete animals and ended with their consumption and additional utilization of particular elements (e.g., antler usage as knapping hammers). Fallow deer are the most abundant species at GBY and are represented by all anatomical elements, indicating that hominins had primary access to complete animals, likely by hunting. The systematic butchering of fallow deer involved several successive stages, documented in characteristic damage marks on the bones. These included skinning (evidenced by cut marks on crania, metapodials, and phalanges), disarticulation that included separation of the skull (evidenced by cut marks and hack marks on atlases and mandibles) as well as separation of forelimb and hindlimb elements (evidence by cut marks and hack marks on articulations of limb elements). Cut marks on diverse elements (mandibles, vertebrae, ribs, scapulae, humeri, radii, ulnae, pelves, femora, and tibiae) are evidence of defleshing and filleting. Finally,

(a)

hunting skinning disarticulation defleshing and filleting marrow extraction antler use as hammerstone

(b)

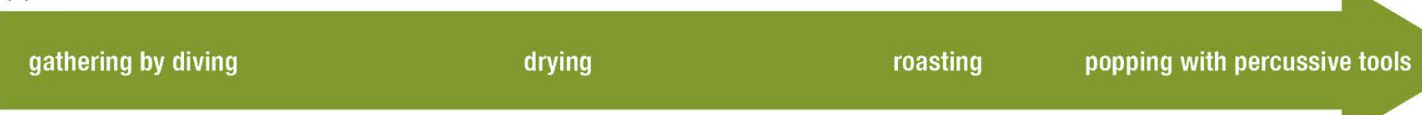

(c)

quarrying giant slabs transportation fragmentation knapping cores selecting cleaver morphologies and modifications

(d)

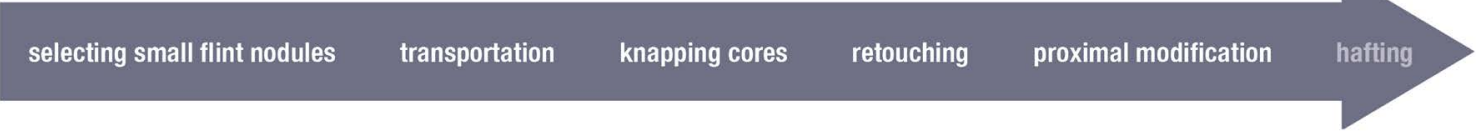

Figure 1. Suggested extended technical sequences expressing expert cognition at the Acheulian site of Gesher Benot Ya'aqov; (a) Fallow deer exploitation (Rabinovich et al., 2008); (b) Prickly water lilly exploitation (Goren-Inbar et al., 2014); (c) Production of basalt cleavers (Goren-Inbar et al., 2018); (d) Production of flint flake-tools (Goren-Inbar et al., 2018); technical stages with archaeological evidence are marked by white font. 
marrow extraction is evidenced by percussion marks on humeri, radii, metapodials, femora, tibiae, and phalanges. This butchering sequence involved the use of sharp edged stone artifacts (e.g. flint flakes) as well as percussive tools (e.g. basalt and limestone hammerstones, anvils). The repetitive occurrence of these bone damage marks is suggestive of a systematic practice that reflect an in-depth knowledge of fallow dear anatomy and a consistent behavioral strategy. Similar location and bone damage markings have been observed in remains from Upper Palaeolithic sites (Rabinovich et al., 2008).

\subsection{Prickly Water Lilly Technical Sequence}

Hominin subsistence at GBY had a wide dietary breadth, enhanced by the use of fire. The highly nutritious water nut Euryale ferox (Prickly water lily, common name Makhana in Bihar, India) occur abundantly throughout the depositional sequence and its fragmented shell remains are found on the archaeological horizons in co-occurrence with hearths, basalt anvils, pitted stones, and hammerstones (Goren-Inbar et al., 2014). This association suggests a specific analogy from the vast ethnographic data on Euryale ferox, as detailed in previous studies (Goren-Inbar et al., 2014).

Euryla ferox is a floating annual aquatic plant growing in shallow low-energy or still-water bodies. The floating leaves and the underwater veins are densely covered with sharp prickles and each plant produces 15 - 20 fruits, each containing 30 - 40 nuts. When the fruit is ripe it releases the nuts that are covered with a mucilaginous arillus that holds them above the water surface for several days, after which they sink to the bottom of the water body and later germinate there (Jha et al., 1991). Considering its prickly nature and its lifecycle, exploitation of this plant necessitates routine observation and hierarchical processing strategies for gathering and processing. Gathering of the nuts must take place after they ripen and sink to the bed of the water body, as they are not washed to the shore. This likely involved diving, as suggested by ethnographic studies (Goren-Inbar et al., 2014). To exploit the kernel of the nuts, the nuts must be dried, and the hard shell removed. This procedure involves double roasting and the use of a variety of percussive tools. Such tools have been found spatially associated on the archaeological horizons at GBY (Alperson-Afil \& Goren-Inbar, 2010). Ethnographic data suggest that popping (a two-stage roasting procedure) of the nuts optimizes the nutritional value. In this procedure the heated moisture contained in the nut vaporizes, releasing sudden pressure and resulting in expansion of the volume of the kernel (Goren-Inbar et al., 2014), as evidenced by the fragmented archaeological nuts.

\subsection{Production of Basalt Cleavers Technical Sequence}

The most frequent cultural remains at GBY are basalt, flint, and limestone artifacts, which constitute the most informative source on hominin behavior and cognition. Basalt was used at GBY for various percussive tools (e.g. anvils, ham- 
merstones), and for the production of bifacial tools: handaxes and cleavers, conforming to the "large flake Acheulian" (LFA) technological tradition (Sharon, 2010). The reduction sequence began with the procurement of massive, thick slabs of alkali-olivine basalt from specific locations within the outcrop, as suggested by the material quality, bedding planes, and the existence of notches on some of these massive slabs (Goren-Inbar, 2011; Goren-Inbar et al., 2018). These were then fractured into more manageable pieces and modified by knapping into giant cores, using at least four core reduction methods: bifacial, slicing, Kombewa and Levallois (Goren-Inbar et al., 2018). The volumetric principle of the slicing method uses the flat surface of the slab as a striking platform from which large flakes are struck, slicing the entire volume of the slab. The bifacial method uses both faces of the slab as striking platforms through alternating removals so that each scar is used as a striking platform for the removal of the next large flake. In the Kombewa method the dorsal face of a very large flake is used as a striking platform for the removal of a large Kombewa flake. This flake is characterized by two ventral faces and a perfectly biconvex cross-section. The Levallois method uses a core with two hierarchically organized and prepared intersecting surfaces, in which the lower part is used as a striking platform for the removal of a flake from the upper convex surface. The morphology of the Levallois flake is thus determined prior to its removal from the core. These different methods produced large flakes that had appropriate morphologies to be used as blanks for bifacial tools. Because these blanks had morphologies similar to those of the desired end products, only minimal additional modification by retouch was required for the final modification, often restricted to the removal of the striking platform and the thinning of the bulb of percussion (Goren-Inbar et al., 2018).

The cleaver is defined based on the configuration of its distal working edge. In the LFA, and in contrast to the convergent tips of a handaxe, the sharp working edge of a cleaver was not formed by retouch but by the intersection of the flat dorsal and ventral planes of a large flake. Such a working edge enables optimal shearing capabilities and controlled penetrations, ideal for heavy cutting and cleaving tasks (Claud et al., 2015). The basic design of the cleaver must have been conceived prior to the removal of the flake blank on which it was produced. A detailed examination of the distal configurations of the GBY cleavers has shown that three different modes were employed in their production (Figure 2). The first used the distal intersection between the two unmodified surfaces of a Kombewa flake. The second used the distal intersection between the ventral face and a remnant of a large negative scar on the dorsal distal end. The third used invasive retouch to delineate an unmodified triangular surface at the dorsal distal edge (Herzlinger et al., 2017) (Figure 2). The observed profile morphologies of the distal ends of the GBY cleavers (i.e. their convexity or concavity) indicate that the production of blanks that bear these types of specific distal configurations could have been achieved only by the Levallois and Kombewa core methods. 
(a)

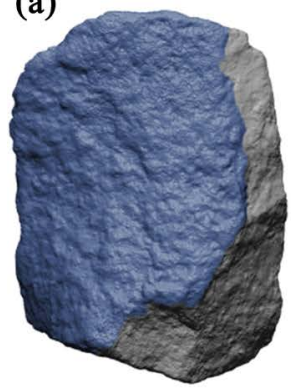

(b)

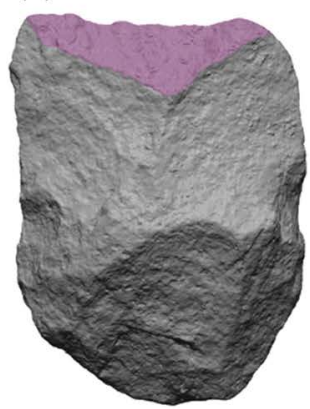

(c)

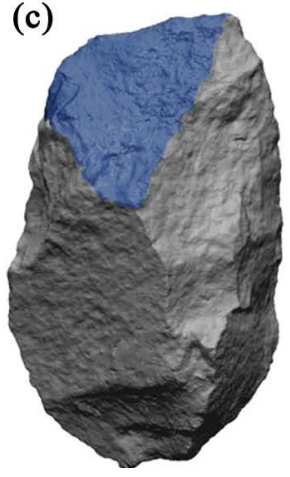

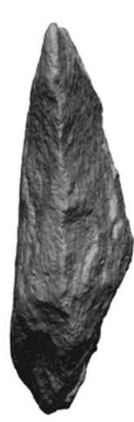
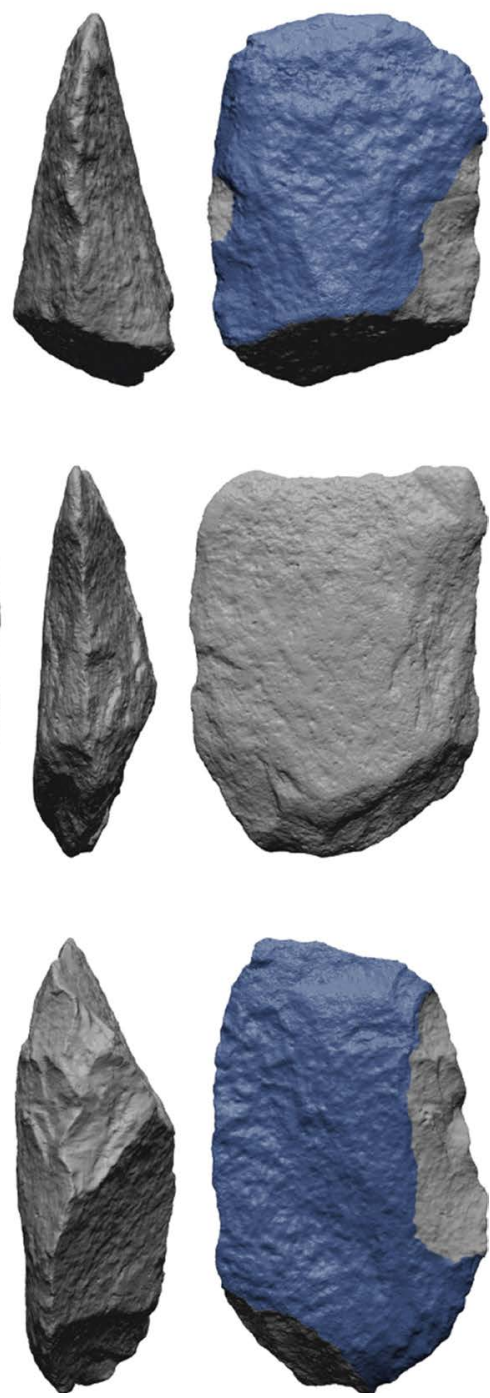

Figure 2. Predetermined types of cleavers: (a) Kombewa (GBY\#100); (b) Large previous scar (GBY\#9896); (c) Delineated (GBY\#5976); Ventral faces are marked in light blue and previous core scar on dorsal face is marked in light violate.

This shows that the decision to produce a cleaver must have taken place in an early phase of the reduction sequence, prior to the modification of the slab fragment into a core (Herzlinger et al., 2017).

\subsection{Proximal Modification of Flint Flake Tools Technical Sequence}

Flint is the most frequent raw material used at GBY and its assemblages are characterized by the small size of the artifacts (Goren-Inbar et al., 2018). The reduction sequence of flint tools began in the selection of small flint nodules and their transportation to the site. There, flint knapping focused on reducing the volume of very small cores to produce small flakes. The following stage in the reduction sequence was the modification of these flakes into the desired target productssmall retouched flakes (37.9\% tools out of the flint flake assemblages, including 
side-scrapers, notches, denticulates; (Goren-Inbar et al., 2018)). Many of the flakes underwent an additional reduction stage, expressed by the removal of their striking platform to acquire a flat, thin surface. Both modifications, retouch and proximal thinning, required precision and dexterity and involved the use of hammerstones of different sizes and hardness. The morphology of the newly obtained proximal area is varied (pointed, curved or straight), suggesting that these flakes were prepared for hafting (Alperson-Afil \& Goren-Inbar, 2016).

\section{GBY Hominin Cognition}

Assessment of cognition using archaeological evidence requires the judicious application of formal cognitive models (Garofoli \& Haidle 2014; Wynn \& Coolidge 2017). Cognitive science does not yet offer a comprehensive model of technical cognition per se. However, studies of modern expert cognition in domains as varied as chess, medical diagnosis, and sport provide models of complex, multifaceted thinking (de Groot, 1965; Ericsson \& Kintsch, 1995; Gobet, 2016). Expertise is a well-studied variety of thinking that powers many of our most impressive performances but is arguably not limited to exceptional individuals (Wynn \& Coolidge, 2014). It is an ecologically valid (Gobet, 2016) variety of thinking deployed in real-world circumstances, and relies on a medley or cognitive resources including perception, motor memory and control, routinized sequences, and executive decision making (de Groot, 1965; Gobet, 1998; Ericsson \& Delaney, 1999; Ericsson et al., 2000; Gobet \& Simon, 2000). Expert cognition is thus an appropriate cognitive model for interpreting Palaeolithic remains, especially the technical and foraging remains that constitute the vast majority of Palaeolithic evidence (Wynn \& Coolidge, 2014; Herzlinger et al., 2017; Wynn et al., 2017).

The most well-developed models of expert cognition focus on its memory components (Gobet, 1998; Ericsson \& Delaney, 1999). Experts demonstrate almost instant access to huge amounts of task-relevant information stored in long-term memory (LTM). The key to this ability lies in the way expertise organizes this information. A 'retrieval structure' is a well-learned chunk (Simon \& Chase, 1973) of information stored in LTM and activated in WM (Baddeley, 2007). It consists of a set of cues linked by association to much larger encodings of information in LTM. For example, the chess cue 'King's Indian Defense' instantly accesses the position of thirty-two pieces on sixty-four squares over several successive moves, a feat of attention far beyond the capacity of WM alone. Retrieval structures are not simple chunks of data. They organize information into schemas (Arbib, 2005) that prioritize tasks and direct attention. These schemas include template 'slots' that accommodate alternate values and facilitate the rapid incorporation of new information (Gobet, 2016), an organization that enables rapid problem assessment via pattern detection and selective search, flexibility in response to a huge range of stimuli, automaticity of response, and facility in learning new task-relevant information. Flexibility is a key element in 
expert cognition, but it is not akin to creativity. Instead of creating new solutions in the face of surprises in the task environment, which would be risky, the expert instead falls back on the huge range of well-learned solutions to which he or she has virtually instant access. The creation and solidification of chunks, including retrieval structures, relies on the evolutionarily old learning mechanism of association. Thus, repetition is necessary, and expert cognition is famous for requiring thousands of repetitions, and years of dedicated practice to acquire mastery (Ericsson et al., 2000; Gobet \& Simon, 2000). In sport and craft production, retrieval structures consist almost entirely of pattern recognition and cues linked directly to motor procedures. Although words can act as cues, retrieval structures are not language dependent.

How does expert cognition evolve? A retrieval structure is not a simple trait; rather, it is a medley of well-learned patterns and responses underpinned by the cognitive resources of perception, long-term memory, and cognitive control. Natural selection can and certainly did act on all of these components. Of particular saliency are the organizational features of retrieval structures, which incorporate not just LTM capacity but also schema formation. WM capacity per se is of comparatively minor relevance, but cognitive control mechanisms such as response inhibition and task switching are essential to task-relevant, goal-directed performance. Thus, the power and scope of retrieval structures could have evolved via enhancement of any or all of the basic cognitive abilities.

The data from GBY indicates that these hominins relied on expert cognition in their knapping, hunting and gathering activities. The variety of evidence from GBY provides a rich set of examples, with the lithic reduction sequences and gathering of prickly water lily nuts being especially informative. The nested organization of stone tool manufacture, with stages and sub-stages, multiple discrete steps, and decision points leading along alternative pathways to a variety of end products, is precisely the kind of organization that guides modern craft production (Keller \& Keller, 1996; Wynn \& Coolidge, 2014). It was almost certainly powered by expert cognition; indeed, as with modern craft production, the automaticity of expert retrieval structures would have been the optimal cognitive strategy. In the manufacture of basalt cleavers, for example, the GBY knappers possessed multiple alternatives stored in long-term memory. The variety of alternatives enabled the knapper to respond flexibly, making choices based on perceptual cues provided by the type and geometry of the raw material, the nature of earlier knapping actions and decisions, and the type of tool they intended to make. This was not simple iterative knapping. The knapper also needed to monitor multiple sub-goals while knapping (e.g., thinning the bulb of percussion, weight reduction, and edge delineation), which required shifts in attention and task switching. Thus, GBY knapping required not just well-learned procedural routines, but the cognitive control resources of WM, all organized into well-learned schemas of expert retrieval structures.

The evidence of fallow deer exploitation corroborates the GBY hominins' re- 
liance on well-learned expert routines that incorporated a variety of tools and motor procedures introduced at different points in a temporally extended sequence of activities.

An even more impressive example of temporally extended action plans is provided by the palaeobotanical evidence for exploitation of prickly water lily nuts. Ethnographic evidence provides a variety of specific examples of modern people utilizing this resource, and all share a basic organization-scheduling according to life-cycle of the plant, diving to recover nuts, carrying with containers of some sort, drying and cleaning, roasting, and pounding to pop or remove the shells. The GBY hominins must have followed this basic outline. This required a variety of discrete routines (and retrieval structures), and sub routines. Unlike lithic reduction, water lily processing required retrieval structures tied to different materials and different contexts, all integrated into an overarching plan of action. Moreover, each of these routines required a different set of skills; one's ability to maintain fire would not transfer to one's ability to dive. And some of these routines (e.g., fire maintenance (Twomey, 2013)) subsumed elaborate sets of procedures in their own right. As with stone knapping, these routines and sub-routines could have been executed using the LTM and WM of expert retrieval structures. But one feature of gathering prickly water lily nuts suggests something more. The activity required two dependent but temporally disjunct stages. The final pay-off-edible nuts-required delayed execution, with hours, perhaps even days, intervening while the nuts dried. This hiatus in operational sequence is quite informative. Such delayed execution required prospective memory, the ability to remember to perform a task at a future time (Einstein \& McDaniel, 2005). The GBY hominins had to remember to complete the temporally disjunct task of prickly water lily nut processing. Stone knapping and fallow deer processing also had temporal breaks, but such a long temporal hiatus was not a necessary component of the operational sequence, and could have played out via more or less continuous activity episodes interspersed with carrying. For water lily processing other activities almost certainly intervened, each such activity drawing attention away from water lily processing. The GBY hominins may have kept the water lily task in attention by regular self-cueing, but this would have taxed a limited WM capacity. It is more likely that prospective memory was a component of the overarching retrieval structure of water lily utilization.

\section{Conclusion}

In sum, the scope and variety of technically enabled hunting and gathering activities evident at GBY appears to have been quite modern. This was not a foraging system that fell mid-way between ape and human foraging. It was indistinguishable in most respects from that practiced by modern hunters and gatherers. From a cognitive perspective, the activities evident from the archaeological remains could have been organized via the cognitive resources of expert retrieval structures, including long-term memory, cognitive control, and prospec- 
tive memory.

How, then does GBY expertise compare to that of modern hunters and gatherers? One advantage of the expertise model is that it provides theoretical grounding for comparison. How many retrieval structures were necessary for lithic expertise at GBY, and for water lily processing? Preservation of course seriously truncates our ability to compare prehistoric actors to modern humans, or even to more recent phases of the Palaeolithic. For example, reconstructions of action sequences necessary for bow and arrow production and use in the Middle Stone Age of South Africa clearly exceed the raw amount of information evident in GBY procedures (Lombard \& Haidle, 2012). But in the case of water lily processing an extensive ethnographic record, and the processing requirements of the plant itself, provide more grounds for the comparison. The GBY and ethnographic procedures are in this case very similar, and almost certainly relied on a similar number of retrieval structures. Moreover the retrieval structures themselves were comparable, including an important role for prospective memory. Thus there are good reasons for concluding that long-term memory capacity itself has evolved since the time of GBY.

In other respects GBY minds were also not yet modern. Compared to modern technical culture, two features are completely missing from the 100,000-year GBY sequence-innovation and symbolic culture. Technical innovation did occur during the one-and-half-million year duration of the Acheulean techno-tradition, but it was very rare. Even though expert retrieval structures provided flexibility, they were not inherently innovative; other cognitive resources underpin creativity (Wynn \& Coolidge, 2014). Nor does GBY present any evidence of artifacts that were clearly material symbols. Both creativity and symbolism are components of modern technical cognition, but at the time of GBY these do not yet appear to have been regular components of the hominin mind.

Technical expertise is a highly important, if underappreciated component of human evolutionary success. Symbolism and language receive the lion's share of attention in discussions of human cognitive evolution, but expertise has arguably been just as important, and has deeper roots. The GBY evidence indicates that it has been an important component of human thinking for at least 800,000 years, and in this respect the GBY hominins resemble modern humans far more than they resemble earlier hominins.

\section{Conflicts of Interest}

The authors declare no conflicts of interest regarding the publication of this paper.

\section{References}

Alperson, N., Sharon, G., Zohar, I., Biton, R., Melamed, Y., Kislev, M. E., Goren-Inbar, N. et al. (2009). Spatial Organization of Hominins Activities at Gesher Benot Ya'aqov, Israel. Science, 326, 1677-1680. https://doi.org/10.1126/science.1180695

Alperson-Afil, N., \& Goren-Inbar, N. (2010). The Acheulian Site of Gesher Benot Ya'aqov 
Volume II: Ancient Flames and Controlled Use of Fire. Dordrecht: Springer. https://doi.org/10.1007/978-90-481-3765-7

Alperson-Afil, N., \& Goren-Inbar, N. (2015). Scarce But Significant: The Limestone Component of the Acheulian Lithic Assemblages of Gesher Benot Ya'aqov, Israel. In M. N. Haidle, N. Conard, \& M. Bolus (Eds.), The Nature of Culture (pp. 41-56). New York: Springer. https://doi.org/10.1007/978-94-017-7426-0_5

Alperson-Afil, N., \& Goren-Inbar, N. (2016). Acheulian Hafting: Proximal Modification of Small Flint Flakes at Gesher Benot Ya'aqov, Israel. Quaternary International, 411, 34-43. https://doi.org/10.1016/j.quaint.2015.12.068

Arbib, M. (2005). Modules, Brains and Schemas. In H.-J. Kreowski, U. Montanari, F. Orejas, G. Rozenberg, \& G. Taentzer (Eds.), Formal Methods in Software and Systems Modeling (pp. 153-166). Lecture Notes in Computer Science (Including Subseries Lecture Notes in Artificial Intelligence and Lecture Notes in Bioinformatics) Vol. 3393. Berlin: Springer. https://doi.org/10.1007/978-3-540-31847-7_9

Ashkenazi, S., Klass, K., Mienis, H. K., Spiro, B., \& Abel, R. (2010). Fossil Embryos and Adult Viviparidae from the Early-Middle Pleistocene of Gesher Benot Ya'aqov, Israel: Ecology, Longevity and Fecundity. Lathaia, 43, 116-127.

https://doi.org/10.1111/j.1502-3931.2009.00178.x

Baddeley, A. (2007). Working Memory, Thought, and Action. Oxford: Oxford University Press. https://doi.org/10.1093/acprof:oso/9780198528012.001.0001

Barnard, P. (2010). From Executive Mechanisms Underlying Perception and Action to the Parallel Processing of Meaning. Current Anthropology, 52, S39-S54. https://doi.org/10.1086/650695

Bednarik, R. (2003). A Figurine from the African Acheulian. Current Anthropology, 44, 405-413. https://doi.org/10.1086/374900

Berlant, T., \& Wynn, T. (2018). First Sculpture: Handaxe to Figure Stone. Chicago, IL: Studio Blue.

Biton, R., Bailon, S., Sharon, G., Goren-Inbar, N., \& Rabinovich, R. (2018). Pleistocene Amphibians and Squamates from the Upper Jordan Rift Valley: Assemblages from Gesher Benot Ya'aqov (MIS 20-18) and Nahal Mahanayeem Outlet (MIS 4/3). Quaternary Research, 91, 345-366.

Bril, B., Smaers, J., Steele, J., Rein, R., Nonaka, T., Dietrich, G., Roux, V. et al. (2012). Functional Mastery of Percussive Technology in Nut-Cracking and Stone-Flaking Actions: Experimental Comparison and Implications for the Evolution of the Human Brain. Philosophical Transactions of the Royal Society of London, B, 367, 59-74. https://doi.org/10.1098/rstb.2011.0147

Claud, E., Deschamps, M., Colonge, D., Mourre, V., \& Thiébaut, C. (2015). Experimental and Functional Analysis of late Middle Paleolithic Flake Cleavers from Southwestern Europe (France and Spain). Journal of Archaeological Science, 62, 105-127. https://doi.org/10.1016/j.jas.2015.05.013

Cole, J. (2017). Accessing Hominin Cognition: Language and Social Signalling in the Lower to Middle Palaeolithic. In T. Wynn, \& F. Coolidge (Eds.), Cognitive Models in Palaeolithic Archaeology (pp. 157-196). Oxford: Oxford University Press. https://doi.org/10.1093/acprof:oso/9780190204112.003.0008

Coolidge, F. L., Wynn, T., Overmann, K. A., \& Hicks, J. M. (2015). Cognitive Archaeology and the Cognitive Sciences. In E. Bruner (Ed.), Human Paleoneurology (pp. 177-208). Cham: Springer. https://doi.org/10.1007/978-3-319-08500-5_8

Coolidge, F., \& Wynn, T. (2001). Executive Functions of the Frontal Lobes and the Evolutionary Ascendancy of Homo Sapiens. Cambridge Archaeological Journal, 11, 255-260. 
https://doi.org/10.1017/S0959774301000142

Coolidge, F., \& Wynn, T. (2018). The Rise of Homo Sapiens: The Evolution of Modern Thinking. Oxford: Oxford University Press.

De Groot, A. (1965). Thought and Choice in Chess. The Hague: Mouton.

Dunbar, R., Gamble, C., \& Gowlett, J. (2014). Lucy to Language: The Benchmark Papers. Oxford: Oxford University Press.

https://doi.org/10.1093/acprof:osobl/9780199652594.001.0001

Einstein, G., \& McDaniel, M. (2005). Prospective Memory: Multiple Retrieval Processes. Current Directions in Psychological Science, 14, 286-290.

https://doi.org/10.1111/j.0963-7214.2005.00382.x

Ericsson, K. A., \& Kintsch, W. (1995). Long-Term Working Memory. Psychological Review, 102, 211-245. https://doi.org/10.1037/0033-295X.102.2.211

Ericsson, K. A., Patel, V., \& Kintsch, W. (2000). How Experts' Adaptations to Representative Task Demands Account for the Expertise Effect in Memory Recall: Comment on Vicente and Wang (1998). Psychological Review, 107, 578-592.

https://doi.org/10.1037/0033-295X.107.3.578

Ericsson, K., \& Delaney, P. (1999). Long-Term Working Memory as an Alternative to Capacity Models of Working Memory in Everyday Skilled Performance. In A. Miyake, \& P. Shah (Eds.), Models of Working Memory: Mechanisms of Active Maintenance and Executive Control (pp. 257-297). Cambridge: Cambridge University Press. https://doi.org/10.1017/CBO9781139174909.011

Feibel, C. S. (2004). Quaternary Lake Margins of the Levant Rift Valley. In N. Goren-Inbar, \& J. D. Speth (Eds.), Human Paleoecology in the Levantine Corridor (pp. 21-36). Oxford: Oxbow Books. https://doi.org/10.2307/j.ctvh1dtct.8

Feizi, N., Nasab, H. V., \& Wynn, T. (2018). Consider the Third Dimension: A New Approach for Measuring the Symmetry of the Middle Paleolithic Points of the Mirak Site. Comptes Rendus Palevol, 17, 388-398. https://doi.org/10.1016/j.crpv.2017.11.004

Gärdenfors, P., \& Högberg, A. (2017). The Archaeology of Teaching and the Evolution of Homo Docens. Current Anthropology, 58, 188-208. https://doi.org/10.1086/691178

Garofoli, D., \& Haidle, M. N. (2014). Epistemological Problems in Cognitive Archaeology: An Anti-Relativistic Proposal towards Methodological Uniformity. Journal of Anthropological Sciences, 92, 7-14.

Gobet, F. (1998). Expert Memory: A Comparison of Four Theories. Cognition and Emotion, 66, 115-152. https://doi.org/10.1016/S0010-0277(98)00020-1

Gobet, F. (2016). Understanding Expertise: A Multi-Disciplinary Approach. London: Palgrave. https://doi.org/10.1007/978-1-137-57196-0

Gobet, F., \& Simon, H. (2000). Five Seconds or Sixty? Presentation Time in Expert Memory. Cognitive Science, 24, 651-682. https://doi.org/10.1207/s15516709cog2404_4

Goren-Inbar, N. (2011). Culture and Cognition in the Acheulian Industry: A Case Study from Gesher Benot Ya'aqov. Philosophical Transactions of the Royal Society of London, B, 366, 1038-1049. https://doi.org/10.1098/rstb.2010.0365

Goren-Inbar, N., \& Peltz, S. (1995). Additional Remarks on the Berekhat Ram Figurine. Rock Art Research, 12, 131-132.

Goren-Inbar, N., \& Sharon, G. (2006). Invisible Handaxes and Visible Acheulian Biface Technology at Gesher Benot Ya'aqov, Israel. In N. Goren-Inbar, \& G. Sharon (Eds.), Axe Age: Acheulian Tool-Making from Quarry to Discard (pp. 111-135). London: Equinox.

Goren-Inbar, N., Alperson-Afil, N., Sharon, G., \& Herzlinger, G. (2018). The Acheulian 
Site of Gesher Bnot Ya'aqov. The Lithic Assemblages. Dordrecht: Springer. https://doi.org/10.1007/978-3-319-74051-5

Goren-Inbar, N., Feibel, C. S., Verosub, K. L., Melamed, Y., Kislev, M. E., Tchernov, E., \& Saragusti, I. (2000). Pleistocene Milestones on the Out-of-Africa Corridor at Gesher Benot Ya'aqov, Israel. Science, 289, 944-974.

https://doi.org/10.1126/science.289.5481.944

Goren-Inbar, N., Lister, A., Werker, E., \& Chech, M. (1994). A Butchered Elephant Skull and Associated Artifacts from the Acheulian Site of Gesher Benot Ya'aqov, Israel. Paléorient, 20, 99-112. https://doi.org/10.3406/paleo.1994.4604

Goren-Inbar, N., Melamed, Y., Zohar, I., Akhilesh, K., \& Pappu, S. (2014). Beneath Still Waters-Multistage Aquatic Exploitation of Euryale ferox (Salisb.) during the Acheulian. Internet Archaeology, 37. https://doi.org/10.11141/ia.37.1

Goren-Inbar, N., Sharon, G., Melamed, Y., \& Kislev, M. (2002a). Nuts, Nut Cracking, and Pitted Stones at Gesher Benot Ya'aqov, Israel. PNAS, 99, 2455-2460. https://doi.org/10.1073/pnas.032570499

Goren-Inbar, N., Werker, E., \& Feibel, C. S. (2002b). The Acheulian Site of Gesher Benot Ya'aqov Volume I: The Wood Assemblage (Vol. 1). Oxford: Oxbow Books.

Gowlett, J. (1979). Complexities of Cultural Evidence in the Lower and Middle Pleistocene. Nature Communications, 278, 14-17. https://doi.org/10.1038/278014b0

Hecht, E., Gutman, D., Kreisheh, N., Taylor, S., Kilner, J., Faisal, A., Stout, D. et al. (2014). Acquisition of Paleolithic Tool-Making Abilities Involves Structural Remodeling to Inferior Fronto-Parietal Regions. Brain Structure and Function, 220, 2315-2331. https://doi.org/10.1007/s00429-014-0789-6

Herrmann, E., Call, J., Hernández-Lloreda, M.-V., Hare, B., \& Tomasello, M. (2007). Humans Have Evolved Specialized Skills of Social Cognition: The Cultural Intelligence Hypothesis. Science, 317, 1360-1366. https://doi.org/10.1126/science.1146282

Herzlinger, G., Wynn, T., \& Goren-Inbar, N. (2017). Expert Cognition in the Production Sequence of Acheulian Cleavers at Gesher Benot Ya'aqov, Israel: A Lithic and Cognitive Analysis. PLoS ONE, 12, e0188337. https://doi.org/10.1371/journal.pone.0188337

Jha, V., Kargupta, A. N., Dutta, R. N., Jha, U. N., Mishra, R. K., \& Saraswati, K. C. (1991). Utilization and Conservation of Euryaleferox Salisbury in Mithila (North Bihar), India. Aquatic Botany, 39, 295-314. https://doi.org/10.1016/0304-3770(91)90005-P

Keller, C., \& Keller, J. (1996). Cognition and Tool Use: The Blacksmith at Work. Cambridge: Cambridge University Press.

Lombard, M., \& Haidle, M. N. (2012). Thinking a Bow-and-Arrow Set: Cognitive Implications of Middle Stone Age Bow and Stone-Tipped Arrow Technology. Cambridge Archaeological Journal, 22, 237-264. https://doi.org/10.1017/S095977431200025X

Madsen, B., \& Goren-Inbar, N. (2004). Acheulian Giant Core Technology and Beyond: An Archaeological and Experimental Case Study. Eurasian Prehistory, 2, 3-52.

Malafouris, L. (2013). How Things Shape the Mind: A Theory of Material Engagement. Cambridge, MA: MIT Press. https://doi.org/10.7551/mitpress/9476.001.0001

Martin-Loeches, M. (2017). Art without Symbolic Mind: Embodied Cognition and the Origins of Visual Artistic Behavior. In T. Wynn, \& F. Coolidge (Eds.), Cognitive Modelsn in Palaeolithic Archaeology (pp. 113-132). Oxford: Oxford University Press. https://doi.org/10.1093/acprof:oso/9780190204112.003.0006

Melamed, Y., Kislev, M. E., Geffen, E., Lev-Yadun, S., \& Goren-Inbar, N. (2016). The Plant Component of an Acheulian Diet at Gesher Benot Ya'aqov, Israel. PNAS, 113, 14674-14679. https://doi.org/10.1073/pnas.1607872113 
Mithen, S. (1996). The Prehistory of Mind. London: Thames and Hudson.

Rabinovich, R., \& Biton, R. (2011). The Early-Middle Pleistocene Faunal Assemblages of Gesher Benot Ya'aqov-Taphonomy and Paleoenvironment. Journal of Human Evolution, 60, 357-374. https://doi.org/10.1016/j.jhevol.2010.12.002

Rabinovich, R., Gaudzinski, S., \& Goren-Inbar, N. (2008). Systematic Butchering of Fallow Deer (Dama) at the Early Middle Pleistocene Acheulian Site of Gesher Benot Ya'aqov, (Israel). Journal of Human Evolution, 54, 134-149. https://doi.org/10.1016/j.jhevol.2007.07.007

Rabinovich, R., Gaudzinski-Windheuser, S., Kindler, L., \& Goren-Inbar, N. (2012). The Acheulian Site of Gesher Benot Ya'aqov Volume III: Mammal Taphonomy-The Assemblages of Layers $V-5$ and $V-6$. Dordrecht: Springer. https://doi.org/10.1007/978-94-007-2159-3

Rightmire, G. (2004). Brain Size and Encephalization in Early to Mid-Pleistocene Homo. American Journal of Physical Anthropology, 124, 109-123. https://doi.org/10.1002/ajpa.10346

Schick, K., Toth, N., Garufi, G., Savage-Rumbaugh, E., Rumbaugh, D., \& Sevcik, R. (1999). Continuing Investigations into the Stone Tool-Making Capabilities of a Bonobo (Pan paniscus). Journal of Archaeological Science, 26, 821-832. https://doi.org/10.1006/jasc.1998.0350

Sharon, G. (2010). Large Flake Acheulian. Quaternary International, 223, 226-233. https://doi.org/10.1016/j.quaint.2009.11.023

Sharon, G., \& Goren-Inbar, N. (1999). Soft Percussor Use at the Gesher Benot Ya'aqov Acheulian Site? Mitekufat Haeven, 28, 55-79.

Sharon, G., Alperson-Afil, N., \& Goren-Inbar, N. (2011). Cultural Conservatism against Variability in the Continual Acheulian Sequence of Gesher Benot Ya'aqov, Israel. Journal of Human Evolution, 60, 387-397. https://doi.org/10.1016/j.jhevol.2009.11.012

Simmons, T. (2004). “A Feather for Each Wind That Blows": Utilizing Avifauna in Assessing Changing Patterns in Paleoecology and Subsistence at Jordan Valley Archaeological Sites. In N. Goren-Inbar, \& J. D. Speth (Eds.), Human Paleoecology in the Levantine Corridor (pp. 191-205). Oxford: Oxbow Books. https://doi.org/10.2307/j.ctvh1dtct.19

Simon, H., \& Chase, W. (1973). Skill in Chess. American Scientist, 61, 393-403.

Stout, D., \& Hecht, E. (2017). Evolutionary Neuroscience of Cumulative Culture. Proceedings of the National Academy of Sciences, 114, 7861-7868. https://doi.org/10.1073/pnas.1620738114

Stout, D., Hecht, E., Khreisheh, N., Bradley, B., \& Chaminade, T. (2015). Cognitive Demands of Lower Palaeolithic Tool-Making. PLoS ONE, 10, e0121804.

https://doi.org/10.1371/journal.pone.0121804

Stout, D., Toth, N., Schick, K., Stout, J., \& Hutchins, G. (2000). Stone Tool-Making and Brain Activation: Positron Emission Tomography (PET) Studies. Journal of Archaeological Science, 27, 1215-1223. https://doi.org/10.1006/jasc.2000.0595

Twomey, T. (2013). The Cognitive Implications of Controlled Use of Fire. Cambridge Archaeological Journal, 23, 113-128. https://doi.org/10.1017/S0959774313000085

Wynn, T. (2002). Archaeology and Cognitive Evolution. Behavioral and Brain Sciences, 25, 389-438. https://doi.org/10.1017/S0140525X02000079

Wynn, T., \& Coolidge, F. (2011). The Implications of the Working Memory Model for the Evolution of Modern Cognition. International Journal of Evolutionary Biology, 2011, Article ID: 741357. https://doi.org/10.4061/2011/741357 
Wynn, T., \& Coolidge, F. (2014). Technical Cognition, Working Memory, and Creativity. Pragmatics and Cognition, 22, 45-63. https://doi.org/10.1075/pc.22.1.03wyn

Wynn, T., \& Coolidge, F. (2017). Cognitive Modelsn in Palaeolithic Archaeology. Oxford: Oxford University Press. https://doi.org/10.1093/acprof:oso/9780190204112.001.0001

Wynn, T., Haidle, M. N., Lombard, M., \& Coolidge, F. L. (2017). The Expert Cognition Model in Human Evolutionary Studies. In T. Wynn, \& F. Coolidge (Eds.), Cognitive Models in Paleolithic Archaeology (pp. 21-44). Oxford: Oxford University Press. https://doi.org/10.1093/acprof:oso/9780190204112.003.0002

Zohar, I., \& Biton, R. (2011). Land, Lake, and Fish: Investigation of Fish Remains from Gesher Benot Ya'aqov (Paleo-Lake Hula). Journal of Human Evolution, 60, 343-356. https://doi.org/10.1016/j.jhevol.2010.10.007 